\title{
Knockdown of BRCA2 enhances cisplatin and cisplatin-induced autophagy in ovarian cancer cells
}

\author{
Biao Wan', Leheyi Dai', Li Wang', Ying Zhang', Hong Huang², Guanhua Qian'1 and Tinghe Yu' \\ 'Key Medical Laboratory of Obstetrics and Gynecology, The Second Affiliated Hospital, Chongqing Medical University, Chongqing, China \\ ${ }^{2}$ Hospital of Stomatology, Chongqing Medical University, Chongqing, China
}

Correspondence should be addressed to T Yu: yutinghe@hotmail.com

\begin{abstract}
Clinical implications of the BRCA2 expression level on treatments of ovarian cancer are controversial. Here, we demonstrated that platinum-resistant cancer had a higher percentage of high BRCA2 level $(87.5 \%$ vs $43.6 \%, P=0.001)$, and that patients with a low BRCA2 level in cancer tissues had longer progression-free survival (with a median time of 28.0 vs 12.0 months, $P<0.001$ ) and platinum-free duration (with a median time of 19.0 vs 5.0 months, $P<0.001$ ) compared with those with a high BRCA2 level. In human ovarian cancer cell lines CAOV-3 and ES-2, cisplatin induced an upregulation of the RAD51 protein, which was inhibited after silencing $B R C A 2$; silencing $B R C A 2$ enhanced the action of cisplatin in vitro and in vivo. Knockdown of BRCA2 promoted cisplatin-induced autophagy. Interestingly, the autophagy blocker chloroquine enhanced cisplatin in BRCA2-silenced cells accompanied by an increase in apoptotic cells, which did not occur in BRCA2-intact cells; chloroquine enhanced the efficacy of cisplatin against BRCA2-silenced CAOV-3 tumors in vivo, with an increase in LC3-II level in tumor tissues. Sensitization of cisplatin was also observed in BRCA2-silenced CAOV-3 cells after inhibiting ATG7, confirming that chloroquine modulated the sensitivity via the autophagy pathway. These data suggest that a low BRCA2 level can predict better platinum sensitivity and prognosis, and that the modulation of autophagy can be a chemosensitizer for certain cancers.
\end{abstract}

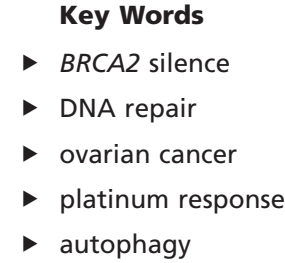

Endocrine-Related Cancer (2018) 25, 69-82

\section{Introduction}

Ovarian cancer has a high response rate $(>80 \%)$ to the initially platinum-based chemotherapy; however, the majority of cases will gradually become refractory and eventually lead to treatment failure (Bookman 2012, Li et al. 2016). Platinum compounds deactivate cancer cells via the formation of DNA crosslinks, thereby causing DNA breaks; resistant cells can repair DNA damages resulting in survival.
The BRCA2 protein directly binds to and regulates the RAD51 protein, an essential molecule for DNA repair via homologous recombination (HR) (FradetTurcotte et al. 2016, Katsuki \& Takata 2016, Yan et al. 2016, Sarwar et al. 2017). BRCA2-deficient cancer cells are hypersensitive to DNA-crosslinking agents such as cisplatin (CDDP), and therefore BRCA2 may be a target for the management of platinum resistance (Sakai et al. 2008, 
Rytelewski et al. 2014, Katsuki \& Takata 2016). As to the relationship between the status of BRCA2 and therapeutic outcome of platinum in ovarian cancer, there yet lacks a consensus: BRCA2 mutation is associated with improved sensitivity to platinum and longer survival in certain trials, but other trials have demonstrated that mutation leads to platinum resistance (Liu et al. 2012, De Picciotto et al. 2016). Furthermore, mechanisms of BRCA2 impacting on the responses to platinum have not been thoroughly elucidated.

Autophagy is commonly considered a survival pathway, but can be cytotoxic when the damage is critical (Arun et al. 2015, Fan et al. 2016). CDDP can induce autophagy, inhibition of autophagy can enhance the action of CDDP because autophagy favors DNA repair, and autophagy may play an important part in chemoresistance in certain cancers (e.g., ovary and skin) (Claerhout et al. 2010, Yu et al. 2011, Zhang et al. 2012, Wu et al. 2016). These data suggest that BRCA2 can modulate the cells' sensitivity to CDDP via the autophagy pathway. However, effects of silencing BRCA2 on CDDP-induced autophagy remain unclear.

In the present study, the association between the expression level of BRCA2 protein and the prognosis in ovarian cancer was clinically analyzed, and then effects of silencing BRCA2 on the sensitivity to CDDP and on autophagy in human ovarian cancer cells CAOV-3 and ES-2 were investigated in vitro and in vivo. Preliminary data suggest that silencing BRCA2 can enhance the action of CDDP and CDDP-induced autophagy.

\section{Materials and methods}

\section{Patients and tumor tissues}

The use of human tissues was ethically approved by the Institutional Review Board of the Second Affiliated Hospital, Chongqing Medical University (Chongqing, China).

Clinical data of 63 cases of ovarian cancer (i.e., age, pathological type/grade, FIGO stage, treatments and therapeutic responses) were collected. All patients underwent debulking surgery followed by platinumbased chemotherapy in the aforementioned hospital, and were followed up (i.e., clinical examinations, serum CA125 and ultrasound/CT scan) every 3 months for 2 years, every 6 months for the next 3 years and then annually (Ledermann et al. 2013). Tumor tissues received immunohistochemical assays. Platinum response was defined as resistance when relapse or progression occurred within 6 months from the last dose and as sensitivity when tumor relapsed after 6 months (Sun et al. 2013). The therapeutic outcome was reflected with the progressionfree survival duration (PFS) and platinum-free duration (PFD). PFS was the interval from the date of initial surgery to the date of progression/recurrence or last contact (censored). PFD was the interval from the end of platinum treatment to the date of progression/recurrence or last contact (censored).

\section{Immunohistochemistry}

Immunohistochemical staining was performed with the SP kit (ZSGB-BIO, Beijing, China) using a rabbit polyclonal anti-BRCA2 antibody (Abcam). Sections were observed by 2 independent pathologists. The expression level of BRCA2 was scored using the percentage of positively stained cells (0: no positive cells; $1: \leq 10 \%$ positive cells; 2 : 11-50\% positive cells; 3: $51-90 \%$ positive cells; $4: \geq 91 \%$ positive cells). Scores 0 and 1 were categorized as a low expression level, and scores 2-4 were categorized as a high expression level (Swisher et al. 2009).

\section{Cells, transfection and drug exposure}

Human ovarian cancer cell lines SKOV3, CAOV-3, ES-2, A2780 and COC1 (identified by STRS; China Center for Typical Culture Collection, Wuhan, China) were cultured in RPMI 1640 medium (Sigma-Aldrich) enriched with $10 \%$ fetal calf serum (Gibco), at $37^{\circ} \mathrm{C}$ and $5 \% \mathrm{CO}_{2}$. The passage number was limited to 30 . The basal level of BRCA2 protein was calibrated, and therefore CAOV-3 and ES-2 cell lines were selected for gene-silencing trials (described later).

A lentiviral vector expressing BRCA2- (shBRCA2) or control-shRNA (NC) was constructed (GenePharma, Shanghai, China). The targeting sequences of siRNA were (5'-AACAACAATTACGAACCAAAC-3') for BRCA2 and (5'-UUCUCCGAACGUGUCACGUTT-3') for NC, respectively (Sakai et al. 2008). Vectors were transferred into CAOV-3 and ES-2 cells with the Polybrene kit (GenePharma). Puromycin (Sigma-Aldrich) was added into the medium to remove uninfected cells.

For in vitro therapeutic trials, cells were treated with CDDP (Qilu Pharm., Jinan, China) and/or chloroquine (CQ; Sigma-Aldrich) for $6 \mathrm{~h}$, and then drugs were washed away. Therefore, both the peak level and the value of 'concentration $\times$ time' of either drug were within the range of human pharmacokinetics, having clinical relevancy (Yu et al. 2016). 
Detecting BRCA2, RAD51, ATG7 and LC3 proteins with Western blot

Proteins were prepared, separated with sodium dodecyl sulfate-polyacrylamide gel electrophoresis and transferred onto a polyvinylidene fluoride membrane (Merck Millipore). Rabbit polyclonal antibodies were used: antiBRCA2, anti-RAD51 (Abcam), anti-LC3 (Abcam), antiATG7 (Cell Signaling Technology) and anti- $\beta$-actin (Bioss Biotechnol., Beijing, China). The secondary antibody was a goat anti-rabbit IgG antibody (ZSGB-BIO). $\beta$-actin served as the reference.

For detecting BRCA2, RAD51 and LC3 after exposure to CDDP $(4 \mu \mathrm{M})$ and/or CQ $(9.69 \mu \mathrm{M}), \mathrm{CAOV}-3$ and ES-2 cells were seeded into a 6-well plate for $48 \mathrm{~h}$ and then received treatments. Proteins were assayed after 24h. CQ can inhibit the fusion of autophagosomes and autolysosomes, leading to the LC3-II accumulation (Mizushima et al. 2010).

\section{Cell viability}

Cells were seeded into a 96 -well plate $\left(5.0 \times 10^{3}\right.$ cells per well) and exposed to CDDP $(0-32 \mu \mathrm{M})$. Cell viability was determined with a CCK-8 assay (Dojindo Lab., Kumamoto, Japan) after $48 \mathrm{~h}$, and then the drug concentration used for functional assays was determined based upon the cell survival curve.

When combining CDDP and CQ, the level of CDDP was 2,4 or $8 \mu \mathrm{M}$, and that of CQ was $9.69 \mu \mathrm{M}$. Cell viability was determined after $24 \mathrm{~h}$.

\section{Colony formation}

Cells were seeded into a 6-well plate (500 cells per well), and then exposed to CDDP $(2 \mu \mathrm{M})$. The number of colony was counted under a microscope after 14 days.

\section{Detecting DNA double-strand break (DSB) using the neutral comet assay}

DSB was detected with the neutral comet assay $0-8 \mathrm{~h}$ after CDDP $(4 \mu \mathrm{M})$ and/or CQ $(9.69 \mu \mathrm{M})$ exposure, and the percentage of comet-formed cells was used to reflect the DSB degree (He et al. 2014).

\section{Detecting the RAD51 foci}

Cells were treated with CDDP $(8 \mu \mathrm{M})$ and/or CQ $(9.69 \mu \mathrm{M})$. After $12 \mathrm{~h}$, cells were fixed with $4 \%$ paraformaldehyde for $10 \mathrm{~min}$, and permeabilized with $0.25 \%$ Triton X-100 in phosphate-buffered saline (PBS). After blocking (3\% bovine serum albumin/3\% goat serum/PBS), a primary antibody against RAD51 was added and incubated at $4^{\circ} \mathrm{C}$ for $16 \mathrm{~h}$. A secondary antibody (Alexa Fluor 594 goat antirabbit IgG antibody; ZSGB-BIO) was added and incubated for $1 \mathrm{~h}$. Nuclei were counterstained with 4', 6-diamidino2-phenylindole dihydrochloride (Invitrogen). Images were captured under a fluorescent microscope (Ti-E; Nikon). Cells with $\geq 5$ RAD51 foci were scored as positive (Sakai et al. 2008). 100 cells per experimental point were evaluated.

Monitoring the autophagy flux with tandem mRFP-GFP fluorescence assay

The autophagy flux was monitored in siBRCA2transfected CAOV-3 cells using a monomeric RFP-GFP tandem fluorescent-tagged LC3 assay (GeneChem, Shanghai, China). Cells were seeded on a coverslip, and then exposed to CDDP $(4 \mu \mathrm{M})$ and/or CQ $(9.69 \mu \mathrm{M})$. After $12 \mathrm{~h}$, cells were fixed with $4 \%$ formaldehyde, washed with PBS and observed under a confocal microscope (Ti-E). 30 cells were checked; yellow puncta (RFP+GFP+) indicated autophagosomes and red dots ( $\left.\mathrm{RFP}^{+} \mathrm{GFP}^{-}\right)$ showed autolysomes (Han et al. 2016). Starvation with EBSS was used as the positive control (ProikasCezanne et al. 2004).

\section{Apoptosis}

Cells were treated with CDDP $(8 \mu \mathrm{M})$ and/or CQ $(9.69 \mu \mathrm{M})$. Apoptotic cells were detected using an Annexin V assay (MultiSciences Biotechnology, Hangzhou, China) after $24 \mathrm{~h}$.

\section{CAOV-3 cells' response to CDDP after silencing ATG7}

This was to confirm that CQ-enhanced CDDP was realized via modulating autophagy, as CQ can also affect other pathways (Zhang et al. 2015). ATG7 (an upstream molecule of LC3) was down-knocked. The infection rate was low when co-transfecting shRNA of BRCA2 and ATG7. siRNA of BRCA2 and/or ATG7 ( 5 ' - CA GAAGGA GUCA CA G CUCUUCCUUA - 3' ; GenePharma), or of NC was transfected into CAOV-3 cells using the siRNA-Mate kit (GenePharma) (Kim et al. 2007). BRCA2 and ATG7 proteins were detected by Western blot after $48 \mathrm{~h}$, and then cells' response to CDDP $(4 \mu \mathrm{M})$ was analyzed. 


\section{In vivo therapeutic trials in CAOV-3 tumors}

The use of animals was ethically and scientifically approved by Chongqing Med. Univ. in compliance with the Guide for the Care and Use of Laboratory Animals. In vivo effects were tested in 2 trials. $5.0 \times 10^{6} \mathrm{NC} / \mathrm{shBRCA2}$ transfected CAOV-3 cells were subcutaneously injected into the left armpit of 4-week-old BALB/C nude mice (Ctr. Lab. Anim., Chongqing Med. Univ.), with 5 animals in each group. CDDP $(5 \mathrm{mg} / \mathrm{kg})$ was injected i.p. every 4 days, and each animal received it 6 times. CQ $(50 \mathrm{mg} / \mathrm{kg})$ was injected i.p. every day for 24 days. Other mice received normal saline. Tumor volume was calibrated every 4 days $\left(\left(\right.\right.$ length $\times$ width$\left.^{2}\right) / 2$ ) (Sun et al. 2013). Mice were euthanized 4 days after the last dose, tumor mass was measured and tumors received examinations.

Trial 1 was performed to determine whether silencing BRCA2 enhanced the anticancer efficacy of CDDP. $\mathrm{NC}$-transfected cells were injected in groups $\mathrm{NC}$ and $\mathrm{NC}+\mathrm{CDDP}$, and shBRCA2-transfected cells were injected in groups shBRCA2 and shBRCA2+CDDP. CDDP was administrated in groups $\mathrm{NC}+\mathrm{CDDP}$ and shBRCA2 + CDDP. Tumors received pathological examinations, and BRCA2 and RAD51 proteins in tumor tissues were detected using an immunohistochemical assay.

Trial 2 determined whether CQ enhanced the action of CDDP in BRCA2-silenced tumors. shBRCA2-transfected cells were injected to form tumors. Mice received CDDP in groups $\mathrm{CDDP}$ and $\mathrm{CDDP}+\mathrm{CQ}$, and $\mathrm{CQ}$ was injected in groups CQ and CDDP $+\mathrm{CQ}$. Tumors received pathological examinations, and LC3 in tumor tissues was detected with Western blot.

\section{Statistics}

Data were processed with the software SPSS 17.0. Analysis of variance and $t$-test were used. The chi-square test was used to compare the association between the BRCA2 expression level and the clinicopathologic variables. PFS and PFD were compared with the Kaplan-Meier method. The critical value was set at $P<0.05$.

\section{Results}

\section{A low expression level of BRCA2 had better chemosensitivity, and longer PFS and PFD}

Clinicopathological characteristics and their relationships to the expression level of BRCA2 protein in cancer tissues are summarized in Table 1 . There was no association between the expression level and age, pathological type/grade, clinical stage, chemotherapy regimen/cycle, or the size of residual tumor. Platinumresistant cancer had a higher BRCA2 level compared with sensitive cancer (with a high expression percentage of $87.5 \%$ (95\% CI: $67.6-97.3 \%$ ) vs $43.6 \%$ (95\% CI:

Table 1 Clinicopathological characteristics and their associations with the expression level of BRCA2 in cancer tissues.

\begin{tabular}{|c|c|c|c|c|}
\hline \multirow[b]{2}{*}{ Clinicopathological variables } & \multirow[b]{2}{*}{ Case no. } & \multicolumn{3}{|c|}{ BRCA2 expression level } \\
\hline & & $\operatorname{Low}(n=25)$ & High $(n=38)$ & $P$ value \\
\hline \multicolumn{5}{|l|}{ Age (year) } \\
\hline$<50$ & 26 & $8(30.8 \%)$ & $18(69.2 \%)$ & 0.225 \\
\hline$\geq 50$ & 37 & $17(45.9 \%)$ & $20(54.1 \%)$ & \\
\hline \multicolumn{5}{|l|}{ Histological type } \\
\hline Serous & 54 & $22(40.7 \%)$ & $32(59.3 \%)$ & 0.958 \\
\hline Clear cell & 9 & $3(33.3 \%)$ & $6(66.7 \%)$ & \\
\hline \multicolumn{5}{|l|}{ Pathological grade } \\
\hline 2 & 20 & $11(55.0 \%)$ & $9(45.0 \%)$ & 0.090 \\
\hline 3 & 43 & $14(32.6 \%)$ & $29(67.4 \%)$ & \\
\hline \multicolumn{5}{|l|}{ FIGO stage } \\
\hline $\mathrm{I} / \mathrm{II}$ & 20 & $10(50.0 \%)$ & $10(50.0 \%)$ & 0.254 \\
\hline III/IV & 43 & $15(34.9 \%)$ & $28(65.1 \%)$ & \\
\hline \multicolumn{5}{|l|}{ Residual tumor } \\
\hline$\leq 1 \mathrm{~cm}$ & 51 & $20(39.2 \%)$ & $31(60.8 \%)$ & 1.000 \\
\hline$>1 \mathrm{~cm}$ & 12 & $5(41.7 \%)$ & $7(58.3 \%)$ & \\
\hline \multicolumn{5}{|l|}{ Chemotherapy regimen } \\
\hline Platinum + paclitaxel & 56 & $23(41.1 \%)$ & $33(58.9 \%)$ & 0.820 \\
\hline Platinum + cyclophosphamide & 7 & $2(28.6 \%)$ & $5(71.4 \%)$ & \\
\hline Cycle & & $6.0(1-12)$ & $5.8(2-12)$ & 0.671 \\
\hline \multicolumn{5}{|l|}{ Platinum response } \\
\hline Sensitive & 39 & $22(56.4 \%)$ & $17(43.6 \%)$ & 0.001 \\
\hline Resistant & 24 & $3(12.5 \%)$ & $21(87.5 \%)$ & \\
\hline
\end{tabular}


27.8-60.4\%), $P=0.001$; and a score of $2.72 \pm 1.24$ vs $1.68 \pm 1.54, P=0.007$ ) (Fig. $1 \mathrm{~A}$ and B). Patients with a low level of BRCA2 in cancer tissues had longer PFS (with a median time of 28.0 (95\% CI: 18.2-37.8) vs 12.0 (95\% CI: 9.6-14.4) months, $P<0.001$ ) and PFD (with a median time of 19.0 (95\% CI: 4.3-33.7) vs 5.0 (95\% CI: 3.0-7.0) months, $P<0.001)$, compared with those with a high level (Fig. 1C and D). The predictive value of a low BRCA2 level for platinum sensitivity was $88.0 \%$, and that of a high level for resistivity was 55.3\% $(P=0.006)$. These data demonstrated that a low expression level of BRCA2 in cancer tissues indicated a better response to platinum.

\section{Silencing BRCA2 suppressed the expression of BRCA2 and RAD51 proteins, and DNA repair}

The basal expression level of BRCA2 in 5 cell lines was assayed to determine appropriate cell lines for genesilencing trials. Western blot demonstrated a higher level in ES-2, CAOV-3 and SKOV3 cell lines, and therefore ES-2 and CAOV-3 (4.7 and 5.7 times higher than that in COC1, respectively) were selected (Fig. $2 \mathrm{~A}$ and $\mathrm{B}$ ).

The level of BRCA2 protein was decreased in shBRCA2infected CAOV-3 or ES- 2 cells $(P=0.003, P=0.034)$. CDDP did not affect the level of BRCA2 protein, but increased the level of RAD51 protein in both cell lines $(P=0.011$, $P=0.012)$; this inductive effect was suppressed after shBRCA2 transfection $(P=0.004, P=0.030)$ (Fig. $2 \mathrm{C}, \mathrm{D}, \mathrm{E}$, F, G and $\mathrm{H}$ ).
The neutral comet assay was performed to detect DSB. The percentage of comet-formed cells decreased gradually after CDDP removal, indicating repair. The value at $2-8 \mathrm{~h}$ in NC-transfected cells was less than that in shBRCA2transfected cells $(P<0.001$ in CAOV-3; $P=0.001$ in ES-2). $80 \%$ DSB were repaired in NC-transfected cells after $8 \mathrm{~h}$, but only 50\% DSB were repaired in shBRCA2-transfected cells (Fig. 2I, J, K and L).

CDDP induced the formation of RAD51 foci, which was decreased after shBRCA2 transfection $(P=0.007$ in CAOV-3; $P=0.004$ in ES-2); in NC- and shBRCA2transfected cells, values were $46.3 \pm 6.5$ vs $26.3 \pm 1.5$ in CAOV- 3 cells, and $54.3 \pm 7.1$ vs $27.7 \pm 2.5$ in ES- 2 cells, respectively (Fig. 2M, N, O and $\mathrm{P}$ ). These data indicated that silencing BRCA2 inhibited the expression of BRCA2 and RAD51 proteins, and decreased DNA repair.

\section{Silencing BRCA2 enhanced the action of CDDP in vitro}

CDDP treatment resulted in a less survival percentage in shBRCA2-transfected cells in comparison with NC-transfected cells $(P<0.001$ in CAOV-3; $P<0.001$ in ES-2), with $\mathrm{IC}_{50}$ values of 1.28 vs $2.97 \mu \mathrm{M}$ in CAOV-3 cells, and 1.37 vs $2.63 \mu \mathrm{M}$ in ES-2 cells, respectively (Fig. 3A and B).

shBRCA2 transfection did not impact on colony formation in both cell lines. Clone inhibition due to CDDP was enhanced after silencing $B R C A 2$, decreasing the clone number $(37.7 \pm 2.5$ vs $8.0 \pm 2.0$ in CAOV-3, $P=0.010$; $34.0 \pm 7.9$ vs $8.3 \pm 1.5$ in ES-2, $P=0.001$ ) (Fig. $3 C, D, E$ and $F$ ).
A
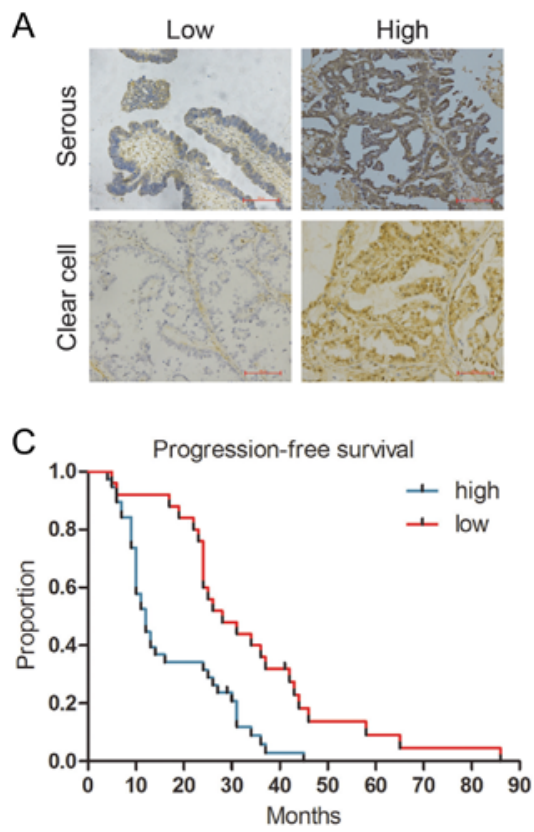
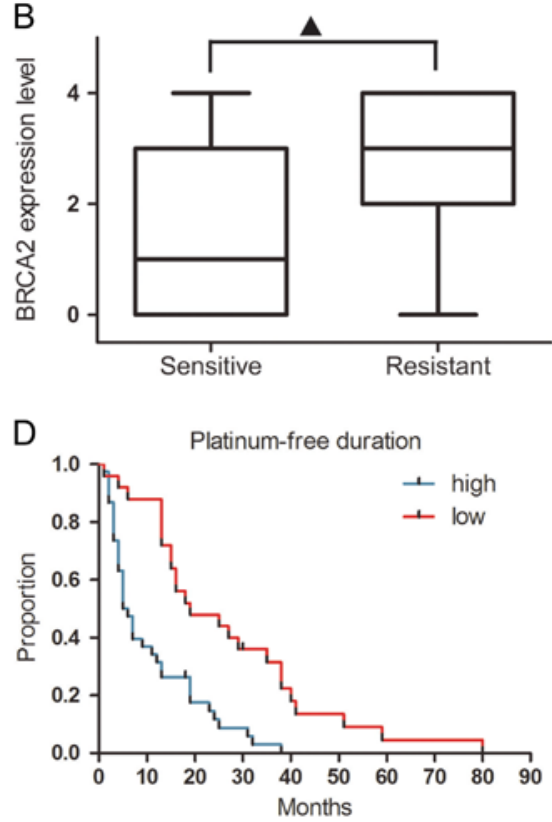

Figure 1

Correlation between the BRCA2 expression level in cancer tissues and the clinical outcome in ovarian cancer patients. Representative immunohistochemical images of BRCA2 expression in cancer tissues (A); the scale was $100 \mu \mathrm{m}$. Scores of the BRCA2 level in platinumresistant and -sensitive cancer (B): resistant cancer had a higher BRCA2 level. A Kaplan-Meier analysis of progression-free survival (C) and platinum-free duration (D): cases with a low BRCA2 level in cancer tissues had longer progression-free survival and platinum-free duration. $\Delta P<0.05$. 


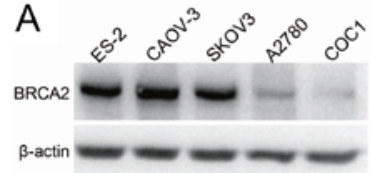

B
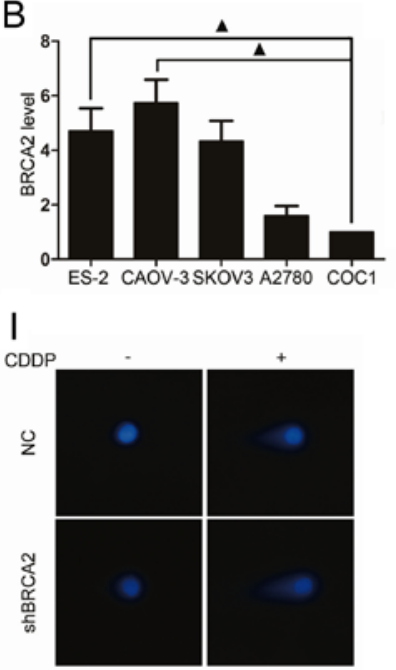

M

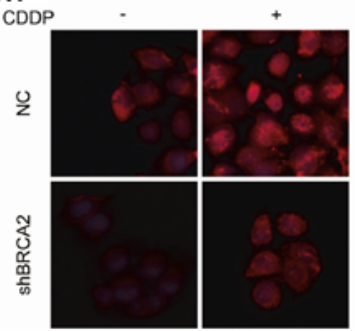

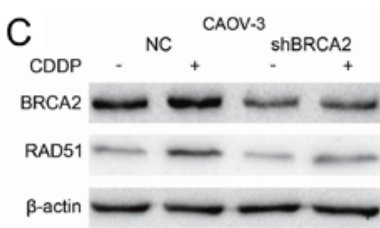

F

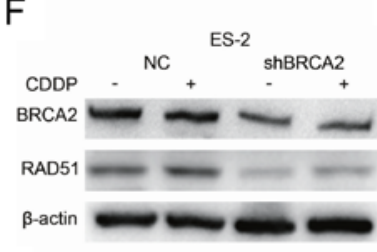

$J$

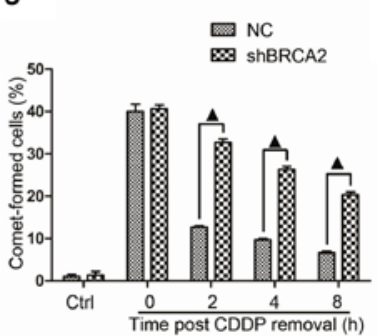

N

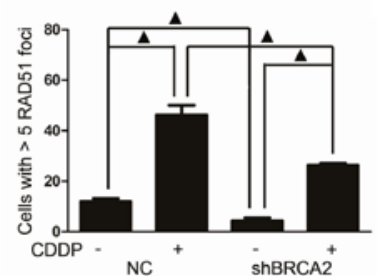

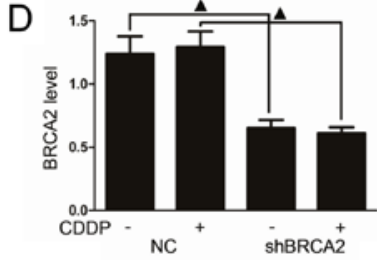

G

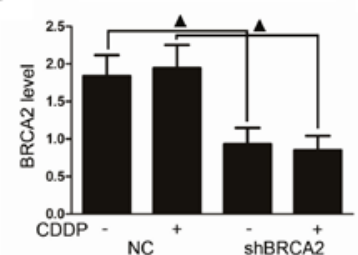

K

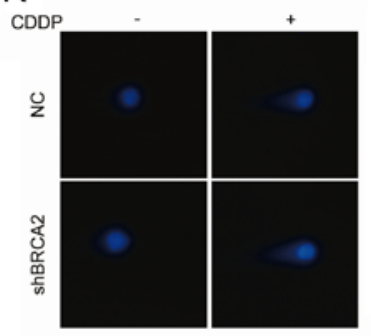

$\mathrm{O}$

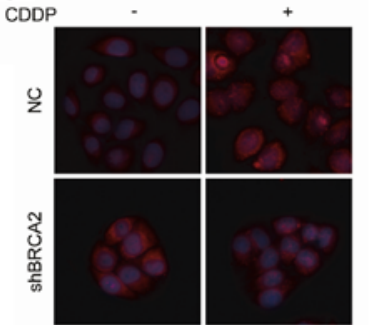

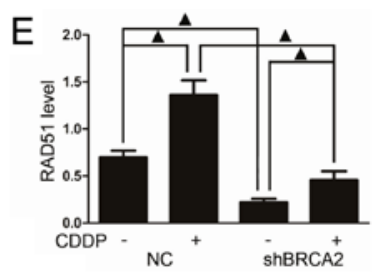

$\mathrm{H}$

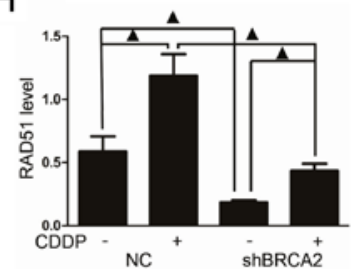

$\mathrm{L}$

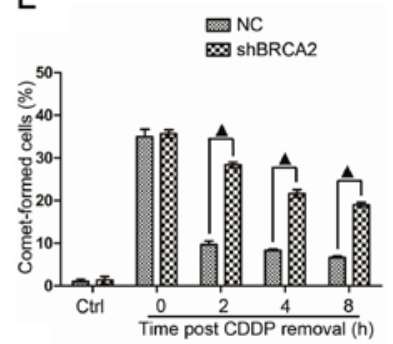

P

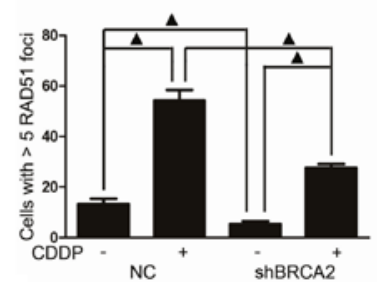

Figure 2

Effects of silencing BRCA2 on the expression of RAD51 and on DNA repair. Basal level of the BRCA2 protein in 5 cell lines (A and B): a higher level was noted in ES-2 and CAOV-3, and therefore these two cell lines were employed for silencing trials. Silencing BRCA2 decreased the level of BRCA2 and RAD51 proteins in CAOV-3 (C, D and E) and ES-2 (F, G and H) cells: CDDP induced upregulation of RAD51, which was suppressed after silencing BRCA2. DSB detected with the neutral comet assay after CDDP exposure $(4 \mu \mathrm{M})$ in CAOV-3 (I and J) and ES-2 (K and L) cells: silencing BRCA2 decreased DNA repair, increasing the percentage of comet-formed cells. RAD51 foci after CDDP exposure ( $8 \mu \mathrm{M})$ in CAOV-3 (M and N) and ES-2 (O and P) cells: CDDP induced the formation of RAD51 foci, which was suppressed in BRCA2-silenced cells. Images were captured under 200x field. Values were mean \pm standard deviation for 3 independent experiments. $\Delta P<0.05$.

These data indicated that silencing BRCA2 enhanced the action of CDDP.

\section{Silencing BRCA2 enhanced CDDP against CAOV-3 tumors in vivo}

Tumor volume and mass in group shBRCA2+CDDP were less than those in group $\mathrm{NC}+\mathrm{CDDP}$, with volumes of $327.7 \pm 68.4$ and $125.7 \pm 21.4 \mathrm{~mm}^{3}$, and masses of $0.42 \pm 0.05$ and $0.24 \pm 0.03 \mathrm{~g}$, in groups $\mathrm{NC}+\mathrm{CDDP}$ and shBRCA2+CDDP, respectively $(P<0.001, \quad P<0.001)$ (Fig. 4A, B and C).
A much lower level of BRCA2 protein was detected in tumors originated from shBRCA2-transfected cells $(3.40 \pm 0.55$ vs $1.00 \pm 0.00, \quad P<0.001)$, demonstrating effective inhibition. CDDP treatment improved the level of RAD51 protein in tumors formed from both NC- and shBRCA2-transfected cells, and this inductive effect was suppressed after shBRCA2 transfection, with scores of $1.40 \pm 0.55, \quad 4.00 \pm 0.00, \quad 1.00 \pm 0.00$ and $1.60 \pm 0.55$ in groups NC, NC+CDDP, shBRCA2 and shBRCA2+CDDP, respectively $(P<0.001)$ (Fig. 4D and E). These data showed that silencing $B R C A 2$ improved the anticancer effect of CDDP in vivo. 

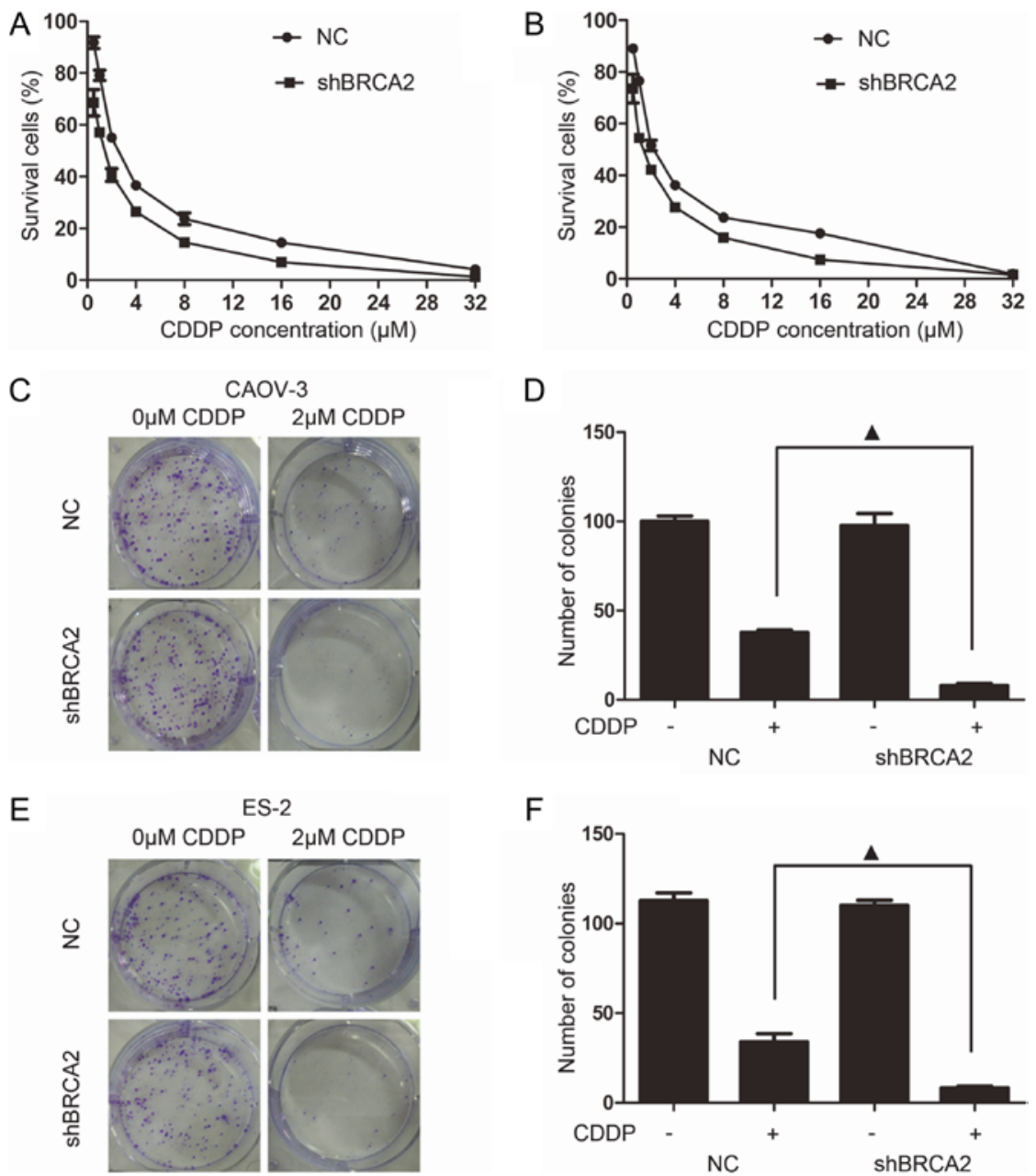
Figure 3
Silencing BRCA2 enhanced the action of CDDP in vitro. Survival percentages after CDDP exposure in CAOV-3 (A) and ES-2 (B) cells: a lower survival fraction occurred in BRCA2-silenced cells. Clone-forming assay in CAOV-3 (C and D) and ES-2 ( $E$ and F) cells: less colony number occurred after silencing BRCA2. Values were mean \pm standard deviation for 3 independent experiments. $\Delta P<0.05$.

\section{Silencing BRCA2 enhanced CDDP-induced autophagy}

CQ with a concentration of $9.69 \mu \mathrm{M}$ caused no cytotoxicity (the percentage of dead cells was $<10 \%$ ), and was therefore used to inhibit autophagy. Basal autophagy was noted in both cell lines, and EBSS-induced autophagy can be blocked by CQ (Supplementary Figs 1 and 2, see section on supplementary data given at the end of this article). CDDP caused autophagy in BRCA2-intact cells $(P<0.001$ in CAOV-3; $P<0.001$ in ES-2); silencing BRCA2 enhanced CDDP-induced autophagy, increasing the LC3-II level $(P=0.004$ in CAOV-3; $P=0.008$ in ES-2) (Fig. $5 \mathrm{~A}$ and $\mathrm{B}$ ).

More $\mathrm{RFP}^{+} \mathrm{GFP}^{+}$and $\mathrm{RFP}^{+} \mathrm{GFP}^{-}$puncta were detected after CDDP exposure, and the number of $\mathrm{RFP}+\mathrm{GFP}+$ puncta was less than that of $\mathrm{RFP}^{+} \mathrm{GFP}^{-}$ones $(P<0.001)$, confirming the autophagy flux. The number of $\mathrm{RFP}^{+} \mathrm{GFP}^{+}$ dots was remarkably increased after adding CQ $(P<0.001)$, demonstrating a blockage of the fusion of autophagosomes and autolysomes (Fig. 5C and D). These findings indicated that silencing BRCA2 can enhance CDDP-induced autophagy.
Suppression of DNA repair due to silencing BRCA2 was further exacerbated by $\mathrm{CQ}$

DNA repair was decreased in shBRCA2-transfected cells, which was exacerbated by CQ $(P=0.003$ in CAOV-3; $P=0.043$ in ES-2); percentages of comet-formed cells at $8 \mathrm{~h}$ were $20.3 \%$ and $34.3 \%$ in CAOV-3 cells, and $19.0 \%$ and $32.7 \%$ in ES-C cells, without and with CQ, respectively (Fig. 6A and B). CQ enhanced the decrease in RAD51 foci due to silencing BRCA2 $(P<0.001$ in CAOV-3; $P=0.002$ in ES-2); the number was $26.3 \pm 1.5$ vs $13.3 \pm 1.5$ in CAOV-3 cells, and $27.7 \pm 2.5$ vs $12.3 \pm 2.5$ in ES- 2 cells, respectively (Fig. 6C and D). These data suggested that CQ can enhance the suppression of DNA repair due to silencing BRCA2.

\section{CQ sensitized the action of CDDP in BRCA2-silenced cells}

CDDP led to a higher percentage of dead cells in shBRCA2transfected cells compared with NC-transfected cells. CQ enhanced CDDP against shBRCA2-transfected cells, resulting in the highest cell death percentage $(P=0.002$ 
A

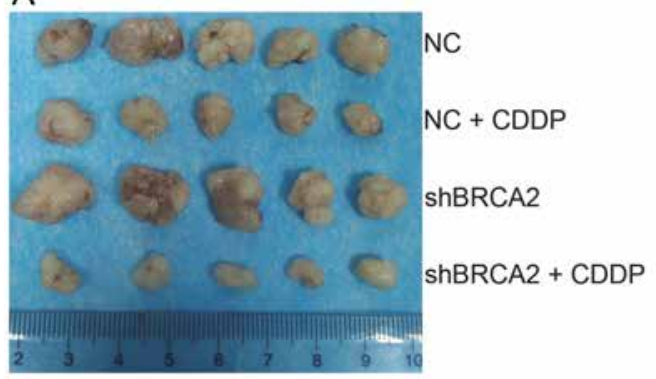

B

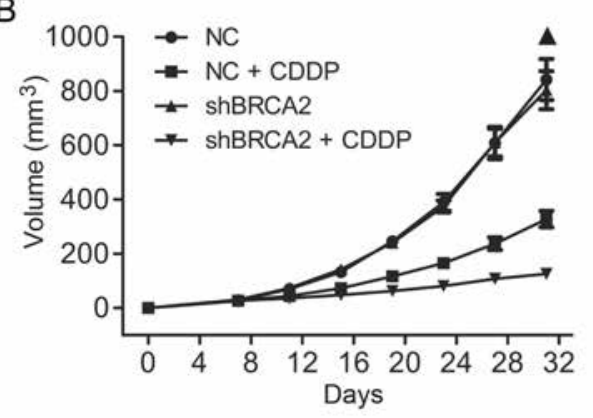

C

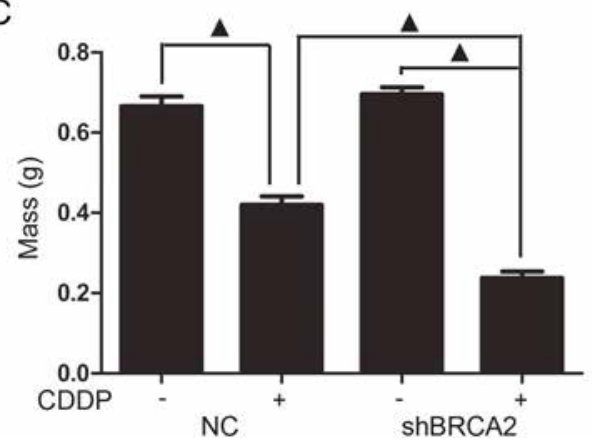

D
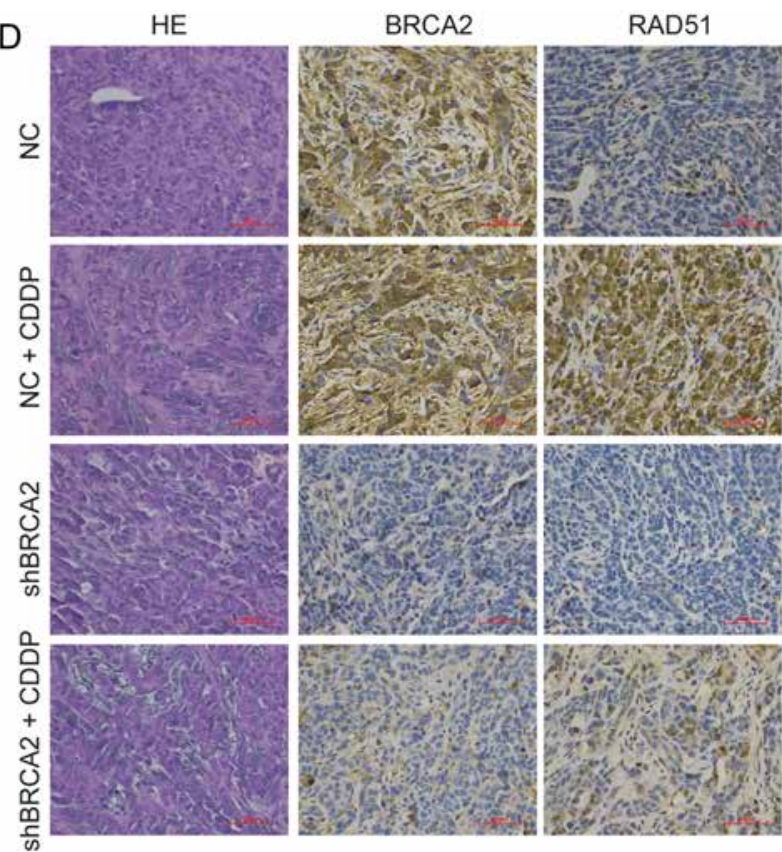

RAD51
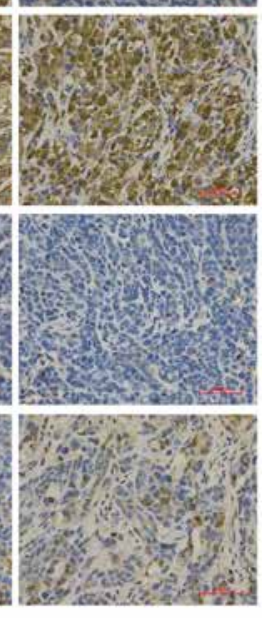

E

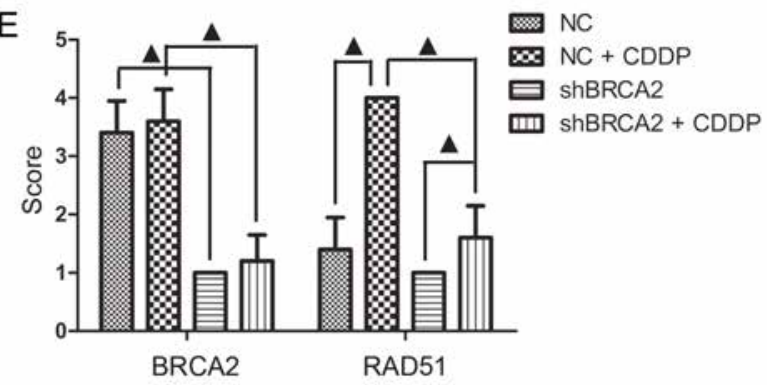

Figure 4

Silencing BRCA2 enhanced the anticancer effect of CDDP on transplanted CAOV-3 tumors in mice $(n=5)$. Gross morphology of tumors (A). Tumor volume and mass (B and $C$ ): CDDP treatment led to the smallest size in BRCA2-silenced tumors. BRCA2 and RAD51 proteins in tumor tissues (D and E): RAD51 was upregulated after CDDP treatment, which was suppressed after silencing $B R C A 2$; the scale was $50 \mu \mathrm{m}$. Values were mean \pm standard deviation. $\Delta P<0.05$.

in CAOV-3; $P=0.001$ in ES-2); values at $8 \mu \mathrm{M}$ CDDP were $53.6 \%$ vs $69.9 \%$ in CAOV-3 cells, and $58.3 \%$ vs $68.5 \%$ in ES-2 cells, without and with CQ, respectively. The enhancement was not detected in NC-transfected cells. Percentages of dead cells at $8 \mu \mathrm{M}$ CDDP were $34.6 \%$ vs $39.0 \%$ in CAOV-3 cells, and $38.4 \%$ vs $41.2 \%$ in ES- 2 cells, without and with $\mathrm{CQ}$, respectively (Fig. 6E and F).

CDDP induced apoptosis. The addition of CQ increased the percentage of apoptotic cells in shBRCA2transfected cells, which did not occur in NC-transfected cells ( $P=0.005$ in CAOV-3; $P=0.003$ in ES-2) (Fig. 6G, $\mathrm{H}$ and I). In NC-transfected cells, values at $8 \mu \mathrm{M}$ CDDP were $10.2 \%$ vs $11.6 \%$ in CAOV-3 cells and $12.0 \%$ vs $12.1 \%$ in ES-2 cells, without and with CQ, respectively; levels were increased to $21.6 \%$ vs $36.6 \%$, and $23.3 \%$ vs $36.4 \%$ in shBRCA2-transfected cells. These data manifested that CQ enhanced cell death and apoptosis attributable to CDDP in BRCA2-silenced cells.

\section{Silencing ATG7 enhanced CDDP against BRCA2-silenced CAOV-3 cells}

BRCA2 and ATG7 proteins were downregulated after siRNA transfection $(P<0.001, P<0.001)$; silencing ATG7 inhibited CDDP-induced autophagy, decreasing the LC3-II level $(P<0.001)$; ATG7 silence did not improve the percentage of dead cells in BRCA2-intact cells, but the value was increased in BRCA2-silenced cells $(P=0.001)$ 
A

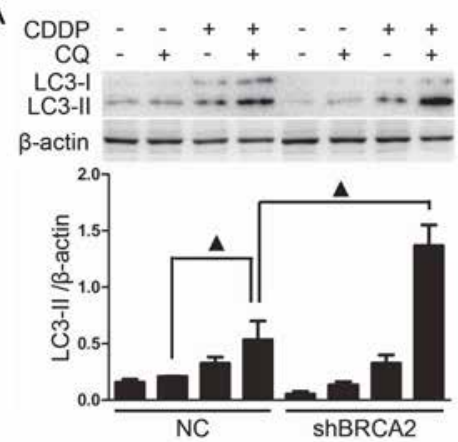

B
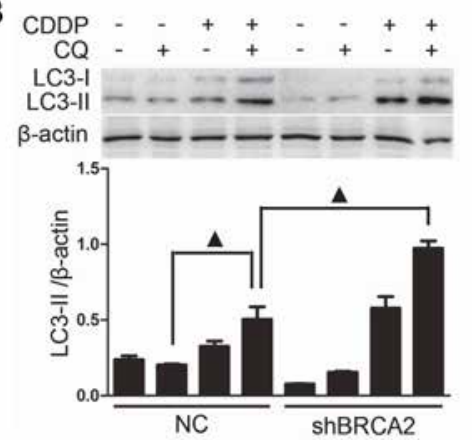

D

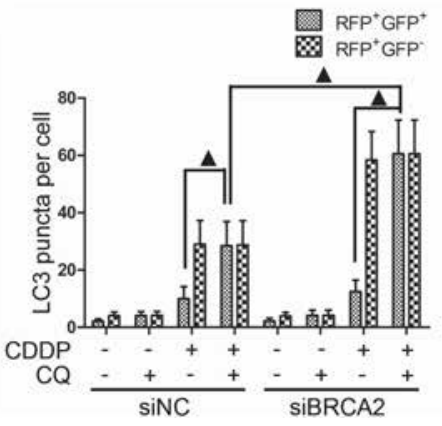

C

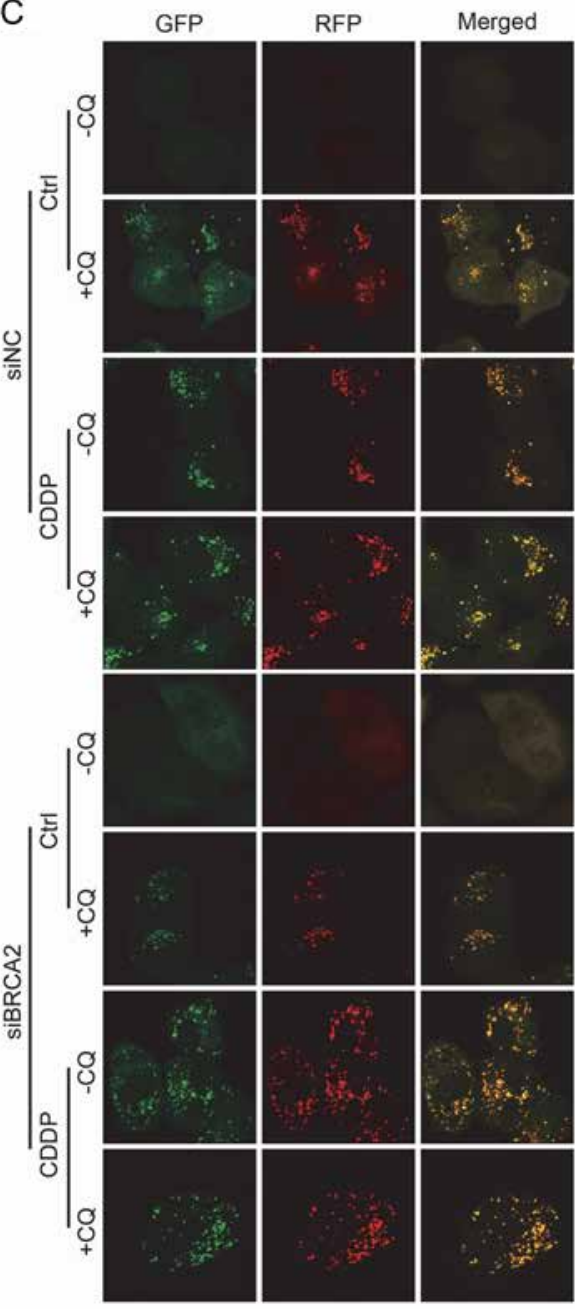

Figure 5

Silencing BRCA2 enhanced CDDP-induced autophagy. Autophagy detected by the LC3-II accumulation in CAOV-3 (A) and ES-2 (B) cells: a higher level was noted in BRCA2-silenced cells. The autophagy flux in CAOV-3 cells observed using the tandem mRFP-GFP fluorescence assay ( $C$ and $D$ ): both yellow (RFP+GFP+) and red (RFP+GFP-) dots were increased after CDDP exposure, and the number of yellow dots was less than that of red dots, demonstrating the occurrence of autophagy flux; a remarkable increase in yellow dots occurred when using CQ, demonstrating the blockage of fusion of autophagosomes and autolysomes. Images were captured under $600 \times$ field. Values were mean \pm standard deviation for 3 independent experiments. $\mathbf{\Delta} P<0.05$.
(Fig. 7). These were consistent with data of using CQ, confirming that CQ modulated the cells' sensitivity via the autophagy pathway.

\section{CQ enhanced CDDP against BRCA2-silenced CAOV-3 tumors in vivo}

Trial 1 demonstrated that silencing BRCA2 enhanced the action of CDDP in vivo, and in vitro trials indicated that $\mathrm{CQ}$ can sensitize CDDP in BRCA2-silenced cells. Therefore, in vivo efficacy of CDDP combined with CQ on BRCA2-silenced tumors was validated. CQ alone did not inhibit tumor growth; CDDP inhibited tumors; the combination of CDDP and CQ led to the smallest tumors $(P<0.001, P<0.001)$, with volumes of $293.6 \pm 35.7$ and $83.6 \pm 28.0 \mathrm{~mm}^{3}$ in groups CDDP and $C D D P+C Q$, respectively (Fig. 8A, B, C and D). The pattern of LC3-II demonstrated intratumoral autophagy in group
$\mathrm{CDDP}+\mathrm{CQ}(P=0.041)$ (Fig. 8E). These data indicated that $\mathrm{CQ}$ enhanced the effect of CDDP against BRCA2silenced tumors, where an increase in autophagy played an important role.

\section{Discussion}

The present data manifested that patients with a low level of BRCA2 protein in cancer tissues had longer PFS and PFD compared with those with a high BRCA2 level. The BRCA2 level did not correlate with pathological stage/grade and the burden of residual lesions; however, platinum-resistant cancer had a higher percentage of high BRCA2 level. These suggest that longer PFS/PFD result from better therapeutic responses, and that BRCA2 can be a prognostic factor in treatments of ovarian cancer. A higher predictive value was noted when using a low BRCA2 level to predict sensitivity. Therefore, a low BRCA2 level 


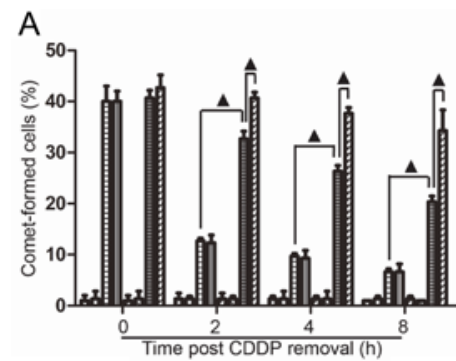

\section{NC}

曰 $\mathrm{NC}+\mathrm{CDDP}$

而 $\mathrm{NC}+\mathrm{CDDP}+\mathrm{CQ}$

III shBRCA2

shBRCA2 + CQ

曲 shBRCA2 + CDDP

shBRCA2 + CDDP + CQ



$\mathrm{E} \square \mathrm{NC}$

NC+CQ

皿 $\operatorname{shBRCA2+CQ}$
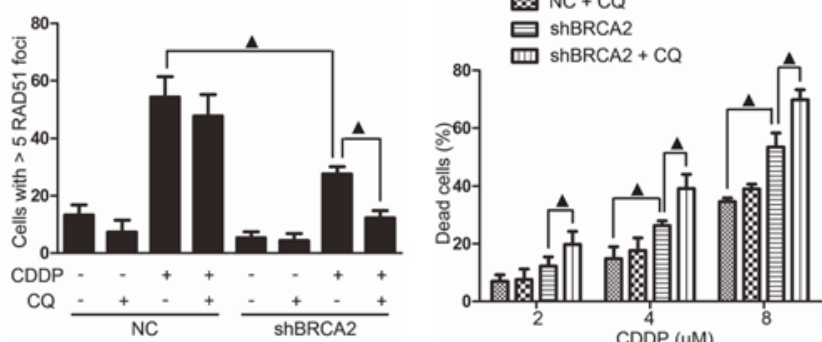

$\mathrm{F} \quad \mathrm{NC}$

m $N$ C + CQ

日 shBRCA2

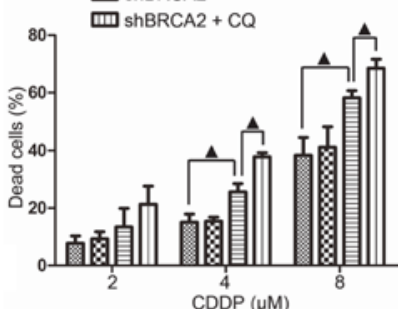

G


Figure 6

CQ enhanced the action of CDDP in BRCA2-silenced cells in vitro. DNA break detected with the neutral comet assay in CAOV-3 (A) and ES-2 (B) cells: DNA repair was suppressed by silencing BRCA2, which was further exacerbated when adding CQ. RAD51 foci in CAOV-3 (C) and ES-2 (D) cells: the foci number was decreased in BRCA2-silenced cells, and adding CQ led to less foci. Percentages of dead cells in CAOV-3 (E) and ES-2 (F) cells: silencing BRCA2 increased the cell death fraction, with the highest value noted when adding CQ. Apoptosis in CAOV-3 (G and H) and ES-2 (G and I) cells: CDDP-induced apoptosis was enhanced after silencing $B R C A 2$, and $C Q$ further increased the percentage of apoptotic cells. Values were mean \pm standard deviation for 3 independent experiments. $\mathbf{\Delta} P<0.05$.

in cancer tissues can provide a better clinical reference, i.e., a low expression level commonly indicated platinum sensitivity but a high level may unnecessarily indicate resistance. The present verdict should be validated in a multicenter trial involving more cases. The mutation status of BRCA2 was commonly considered the determinant of therapeutic outcome (De Picciotto et al. 2016, Milne \& Antoniou 2016); thus, association of the BRCA2 mutation 



Figure 7 CAOV-3 cells' response to CDDP after inhibiting ATG7. BRCA2 and ATG7 proteins (A): levels were decreased after transferring siRNA. Autophagy detected by the LC3 assay (B): silencing BRCA2 enhanced CDDP-induced autophagy, increasing the LC3-II level; this was inhibited after knockdown of ATG7. Cell death percentages after CDDP exposure $(4 \mu \mathrm{M})$ (C): knockdown of ATG7 enhanced CDDP in $B R C A 2$-silenced cells. Values were mean \pm standard deviation for 3 independent experiments. $\mathbf{\Delta} P<0.05$.

status with the expression level should be investigated in following trials.

Platinum agents induced DSB, and cell death resulted from irreparable DSB. DSB can be repaired by HR or non-homologous end joining, resulting in cell survival. BRCA2 was the pivotal molecule in HR, and RDA51 was the downstream effector of BRCA2 (Dungl et al. 2015, Katsuki \& Takata 2016). The present data demonstrated that CDDP induced an increase in the RAD51 protein level in vitro and in vivo (i.e., the signal of DNA damages will initiate repair), which was suppressed in silencing $B R C A 2$. These indicated that $\mathrm{HR}$ was the major mode of DSB repair in ovarian cancer. Silencing BRCA2 enhanced the efficacy of CDDP, where the decrease in RAD51 played an important part. A reduction of RAD51 decreased the HR capacity, thereby exacerbating DSB due to CDDP. Consequently, a higher percentage of comet-formed cells was detected, which caused a less colony number and a higher percentage of dead cells. The apoptosis percentage was increased in BRCA2silenced cells, showing that apoptosis was involved in cell death attributable to DSB. A deeper gap between cell death and apoptosis fractions was noted in both cell lines, suggesting that other modes may also contribute to cell death in BRCA2-silenced cells.

As to the role of autophagy in chemotherapy, data released were controversial (Levine \& Kroemer 2008). The present findings showed that CDDP caused autophagy in BRCA2-intact cells, accompanied by upregulation of the RAD51 protein. These implied that autophagy can favor $\mathrm{HR}$, thereby alleviating the cytotoxicity of CDDP. Zhang et al. (2012) manifested that inhibition of autophagy due to knockdown of nucleus accumbens-1 enhanced the action of CDDP in human ovarian cancer cells, where apoptosis was the cell death pathway. However, the present data demonstrated that silencing BRCA2 enhanced CDDP-induced cell killing but with an increase in autophagy, suggesting that autophagy may relate to cell death. Autophagy was cytotoxic when serious insults occurred (Arun et al. 2015, Yang et al. 2016). Therefore, silencing BRCA2 may have a sensitization effect, which decreased the cell death threshold of DSB leading to cell deactivation; those damages can be commonly repaired in BRCA2-intact cells, resulting in cell survival.

How BRCA2 modulated autophagy remained unclear. Knockdown of BRCA2 enhanced cell death induced by 
A
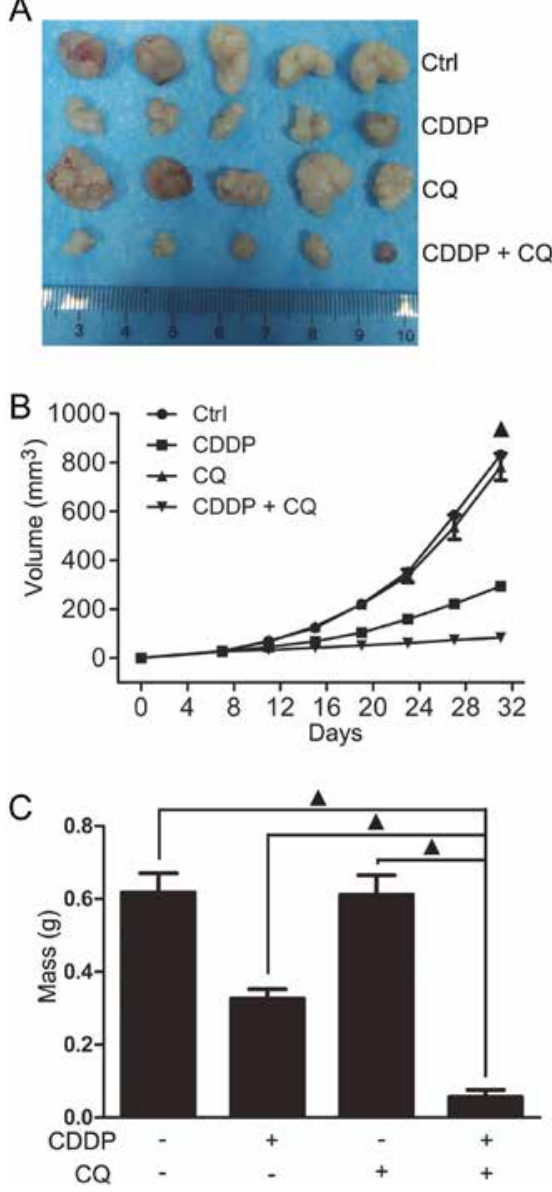

D
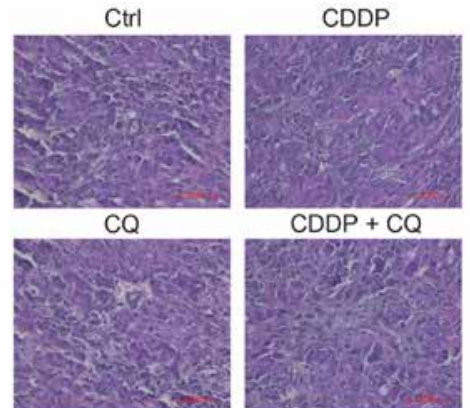

$\mathrm{CDDP}+\mathrm{CQ}$



$E$
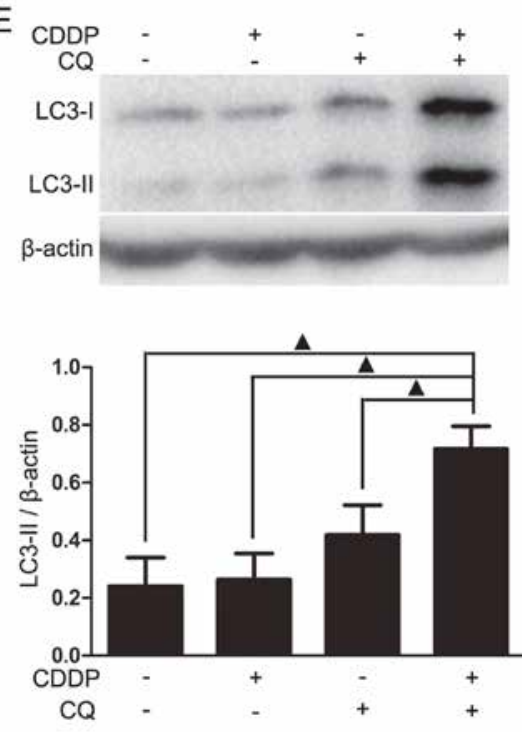

Figure 8

CQ enhanced the anticancer effect of CDDP against BRCA2-silenced CAOV-3 tumors in mice $(n=5)$. Gross morphology of tumors (A). Tumor volume (B) and mass (C): CDDP treatment reduced the tumor, with the smallest tumor when combining CDDP and CQ. Pathological examinations of tumor xenografts (D); the scale was $50 \mu \mathrm{m}$. Autophagy detected by LC3-II accumulation in tumors (E): a higher level was detected in group CDDP $+C Q$. Values were mean \pm standard deviation. $\Delta P<0.05$.
AZ2281 (a PARP inhibitor) in breast cancer cells, where autophagy was involved in cell death via eliminating mitochondria (Arun et al. 2015). DNA damages induced autophagy via the ATM- or PARP1-dependent pathway (Eliopoulos et al. 2016). Intracellular targets of CDDP included both nuclear (i.e., DNA breaks) and cytoplasmic (i.e., production of reactive oxygen species damaging organellae including mitochondria) sites (Brozovic et al. 2010). Silencing BRCA2 impacted on autophagy via modulating the cells' response to CDDP. Silencing BRCA2 increased the amount of DSB via decreasing HR. The damage signal was transmitted to mitochondria via PARP1, ATM, p53, SIRT1, AMPK and PGC1 $\alpha$, causing the dysfunction of mitochondria (Fang et al. 2016). Reactive oxygen species induced by CDDP can directly attack mitochondria. These effects exacerbated damages to mitochondria, arousing autophagy and/or apoptosis. Silencing BRCA2 can also enhance mitochondrial damages directly due to CDDP.

Interestingly, the autophagy blocker CQ enhanced the anticancer activity of CDDP in BRCA2-silenced cells, but this did not occur in BRCA2-intact cells. This was inconsistent with the aforementioned result that autophagy may involve in cell death. The disagreement may relate to intratumoral heterogeneity of ovarian cancer: a cell line consisted of multiple subpopulations with different biological properties (Konstantinopoulos \& Matulonis 2013). Silencing BRCA2 produced a sensitization effect in specific subpopulations, decreasing the DSB threshold to divert autophagy to being cytotoxic. The threshold was not altered in other subpopulations; thus, CQ inhibited DSB repair to enhance CDDP. These effects resulted in synergy, thereby improving the action of CDDP in BRCA2-silenced cells. This deduction can be supported with data in the comet and RAD51 foci assays: the use of CQ increased comets and decreased foci. A remarkable increase in apoptotic cells indicated that apoptosis played an important part in cell death after blocking autophagy. Similar results were observed in chemoresistant ovarian cancer cells COC1/DDP when using ultrasound to reverse resistance: ultrasonic sensitization made certain cells undergo necrosis, although CDDP commonly deactivated cells via apoptosis; concurrent occurrence of apoptosis and necrosis improved the action of CDDP 
(Yu et al. 2015). Enhancement of CDDP was detected in BRCA2-silenced cells after knockdown of Atg7, confirming that CQ-enhanced CDDP was realized via modulating autophagy.

In vivo trials demonstrated that a combination of $B R C A 2$-silenced and CQ improved the anticancer efficacy of CDDP. Therefore, knockdown of BRCA2 combined with CQ may be a strategy to treat resistant ovarian cancers, and CQ can be employed to enhance CDDP against cancers with a low BRCA2 level. A higher level of LC3-II in tumor tissues indicated that autophagy was involved in the anticancer effect. Efficacy of this modality should be validated in an orthotopic cancer model, considering limitations of an ectopic model (Zhang et al. 2016, 2017).

In conclusion, the present data demonstrated that ovarian cancer with a low BRCA2 level had better platinum response and longer PFS/PFD; thus, the BRCA2 level in cancer tissues can predict the therapeutic outcome. Autophagy favored DSB repair in BRCA2-intact cells. Knockdown of BRCA2 can enhance the cytotoxicty of CDDP and can improve autophagy. CQ enhanced CDDP against BRCA2-silenced cells, suggesting that modulation of autophagy can be a chemosensitizer for ovarian cancer with a low BRCA2 level.

\section{Supplementary data}

This is linked to the online version of the paper at https://doi.org/10.1530/ ERC-17-0261.

\section{Declaration of interest}

The authors declare that there is no conflict of interest that could be perceived as prejudicing the impartiality of the research reported.

\section{Funding}

This work was supported with grants from the National Science Foundation of China (31470822) and the State Ministry of Education (SRFDP 20135503130002).

\section{References}

Arun B, Akar U, Gutierrez-Barrera AM, Hortobagyi GN \& Ozpolat B 2015 The PARP inhibitor AZD2281 (Olaparib) induces autophagy/ mitophagy in BRCA1 and BRCA2 mutant breast cancer cells. International Journal of Oncology 47 262-268. (https://doi. org/10.3892/ijo.2015.3003)

Bookman MA 2012 First-line chemotherapy in epithelial ovarian cancer. Clinical Obstetrics and Gynecology 55 96-113. (https://doi. org/10.1097/GRF.0b013e31824b45da)

Brozovic A, Ambriovic-Ristov A \& Osmak M 2010 The relationship between cisplatin-induced reactive oxygen species, glutathione, and
BCL-2 and resistance to cisplatin. Critical Reviews in Toxicology 40 347-359. (https://doi.org/10.3109/10408441003601836)

Claerhout S, Verschooten L, Van Kelst S, De Vos R, Proby C, Agostinis P \& Garmyn M 2010 Concomitant inhibition of AKT and autophagy is required for efficient cisplatin-induced apoptosis of metastatic skin carcinoma. International Journal of Cancer 127 2790-2803. (https://doi.org/10.1002/ijc.25300)

De Picciotto N, Cacheux W, Roth A, Chappuis PO \& Labidi-Galya SI 2016 Ovarian cancer: status of homologous recombination pathway as a predictor of drug response. Critical Reviews in Oncology/ Hematology 101 50-59. (https://doi.org/10.1016/j. critrevonc.2016.02.014)

Dungl DA, Maginn EN \& Stronach EA 2015 Preventing damage limitation: targeting DNA-PKcs and DNA double-strand break repair pathways for ovarian cancer therapy. Frontiers in Oncology 5240. (https://doi.org/10.3389/fonc.2015.00240)

Eliopoulos AG, Havaki S \& Gorgoulis VG 2016 DNA damage response and autophagy: a meaningful partnership. Frontiers in Genetics 7204. (https://doi.org/10.3389/fgene.2016.00204)

Fan J, Liu Y, Yin J, Li Q, Li Y, Gu J, Cai W \& Yin G 2016 Oxygenglucose-deprivation/ reoxygenation-induced autophagic cell death depends on JNK-mediated phosphorylation of Bcl-2. Cellular Physiology and Biochemistry 38 1063-1074. (https://doi. org/10.1159/000443057)

Fang EF, Scheibye-Knudsen M, Chua KF, Mattson MP, Croteau DL \& Bohr VA 2016 Nuclear DNA damage signalling to mitochondria in ageing. Nature Reviews Molecular Cell Biology 17 308-321. (https://doi. org/10.1038/nrm.2016.14)

Fradet-Turcotte A, Sitz J, Grapton D \& Orthwein A 2016 BRCA2 functions: from DNA repair to replication fork stabilization. Endocrine-Related Cancer 23 T1-T17. (https://doi.org/10.1530/ERC-160297)

Han C, Ding Z, Shi H, Qian W, Hou X \& Lin R 2016 The role of probiotics in lipopolysaccharide-induced autophagy in intestinal epithelial cells. Cellular Physiology and Biochemistry 38 2464-2478. (https://doi.org/10.1159/000445597)

He H, Huang H \& Yu T 2014 Detection of DNA damage in sonochemotherapy against cisplatin-resistant human ovarian cancer cells using the modified comet assay. International Journal of Radiation Biology 90 897-902. (https://doi.org/10.3109/09553002.2014.922721)

Katsuki Y \& Takata M 2016 Defects in homologous recombination repair behind the human diseases: FA and HBOC. Endocrine-Related Cancer 23 T19-T37. (https://doi.org/10.1530/ERC-16-0221)

Kim EH, Sohn S, Kwon HJ, Kim SU, Kim MJ, Lee SJ \& Choi KS 2007 Sodium selenite induces superoxide-mediated mitochondrial damage and subsequent autophagic cell death in malignant glioma cells. Cancer Research 67 6314-6324. (https://doi.org/10.1158/0008-5472. CAN-06-4217)

Konstantinopoulos PA \& Matulonis UA 2013 Current status and evolution of preclinical drug development models of epithelial ovarian cancer. Frontiers in Oncology 3 296. (https://doi.org/10.3389/ fonc.2013.00296)

Ledermann JA, Raja FA, Fotopoulou C, Gonzalez-Martin A, Colombo N \& Sessa C 2013. Newly diagnosed and relapsed epithelial ovarian carcinoma: ESMO clinical practice guidelines for diagnosis, treatment and follow-up. Annals of Oncology 24 vi24-vi32. (https://doi. org/10.1093/annonc/mdt333)

Levine B \& Kroemer G 2008 Autophagy in the pathogenesis of disease. Cell 132 27-42. (https://doi.org/10.1016/j.cell.2007.12.018)

Li C, Ding H, Tian J, Wu L, Wang Y \& Xing Y 2016 Forkhead box protein $\mathrm{C} 2$ (FOXC2) promotes the resistance of human ovarian cancer cells to cisplatin in vitro and in vivo. Cellular Physiology and Biochemistry 39 242-252. (https://doi.org/10.1159/000445620)

Liu G, Yang D, Sun Y, Shmulevich I, Xue F, Sood AK \& Zhang W 2012 Differing clinical impact of BRCA1 and BRCA2 mutations in serous 
ovarian cancer. Pharmacogenomics 13 1523-1535. (https://doi. org/10.2217/pgs.12.137)

Milne RL \& Antoniou AC 2016 Modifiers of breast and ovarian cancer risks for BRCA1 and BRCA2 mutation carriers. Endocrine-Related Cancer 23 T69-T84. (https://doi.org/10.1530/ERC-16-0277)

Mizushima N, Yoshimori T \& Levine B 2010 Methods in mammalian autophagy research. Cell 140 313-326. (https://doi.org/10.1016/j. cell.2010.01.028)

Proikas-Cezanne T, Waddell S, Gaugel A, Frickey T, Lupas A \& Nordheim A 2004 WIPI-1 $\alpha$ (WIPI49), a member of the novel 7-bladed WIPI protein family, is aberrantly expressed in human cancer and is linked to starvation-induced autophagy. Oncogene $\mathbf{2 3}$ 9314-9325. (https://doi.org/10.1038/sj.onc.1208331)

Rytelewski M, Tong JG, Buensuceso A, Leong HS, Maleki Vareki S, Figueredo R, Di Cresce C, Wu SY, Herbrich SM, Baggerly KA, et al. 2014 BRCA2 inhibition enhances cisplatin-mediated alterations in tumor cell proliferation, metabolism, and metastasis. Molecular Oncology 8 1429-1440. (https://doi.org/10.1016/j.molonc.2014.05.017)

Sakai W, Swisher EM, Karlan BY, Agarwal MK, Higgins J, Friedman C, Villegas E, Jacquemont C, Farrugia DJ, Couch FJ, et al. 2008 Secondary mutations as a mechanism of cisplatin resistance in BRCA2-mutated cancers. Nature 451 1116-1120. (https://doi.org/10.1038/nature06633)

Sarwar R, Mahjabeen I, Bashir K, Saeed S \& Kayani MA 2017 Haplotype based analysis of XRCC3 gene polymorphisms in thyroid cancer. Cellular Physiology and Biochemistry 42 22-33. (https://doi. org/10.1159/000477109)

Sun C, Li N, Yang Z, Zhou B, He Y, Weng D, Fang Y, Wu P, Chen P, Yang X, et al. 2013 miR-9 regulation of BRCA1 and ovarian cancer sensitivity to cisplatin and PARP inhibition. Journal of the National Cancer Institute 105 1750-1758. (https://doi.org/10.1093/jnci/djt302)

Swisher EM, Gonzalez RM, Taniguchi T, Garcia RL, Walsh T, Goff BA \& Welsch P 2009 Methylation and protein expression of DNA repair genes: association with chemotherapy exposure and survival in sporadic ovarian and peritoneal carcinomas. Molecular Cancer 848. (https://doi.org/10.1186/1476-4598-8-48)

Wu X, Feng X, Zhao X, Ma F, Liu N, Guo H, Li C, Du H \& Zhang B 2016 Role of beclin-1-mediated autophagy in the survival of pediatric leukemia cells. Cellular Physiology and Biochemistry 39 1827-1183. (https://doi.org/10.1159/000447882)

Yan L, Li Q, Li X, Ji H \& Zhang L 2016 Association studies between XRCC1, XRCC2, XRCC3 polymorphisms and differentiated thyroid carcinoma. Cellular Physiology and Biochemistry 38 1075-1084. (https://doi.org/10.1159/000443058)

Yang C, Yang QQ, Kong QJ, Yuan W \& Ou Yang YP 2016 Parthenolide induces reactive oxygen species-mediated autophagic cell death in human osteosarcoma cells. Cellular Physiology and Biochemistry $\mathbf{4 0}$ 146-154. (https://doi.org/10.1159/000452532)

Yu H, Su J, Xu Y, Kang J, Li H, Zhang L, Yi H, Xiang X, Liu F \& Sun L 2011 p62/SQSTM1 involved in cisplatin resistance in human ovarian cancer cells by clearing ubiquitinated proteins. European Journal of Cancer 47 1585-1594. (https://doi.org/10.1016/j.ejca.2011.01.019)

Yu T, Yang Y, Zhang J, He H \& Ren X 2015 Circumvention of cisplatin resistance in ovarian cancer by combination of cyclosporin $\mathrm{A}$ and low-intensity ultrasound. European Journal of Pharmaceutics and Biopharmaceutics 91 103-110. (https://doi.org/10.1016/j. ejpb.2015.02.003)

Yu T, Luo L \& Wang L 2016 Ultrasound as a cancer chemotherapy sensitizer: the gap between laboratory and bedside. Expert Opinion on Drug Delivery 13 37-47. (https://doi.org/10.1517/17425247.2015.108 3008)

Zhang Y, Cheng Y, Ren X, Zhang L, Yap KL, Wu H, Patel R, Liu D, Qin ZH, Shih IM, et al. 2012 NAC1 modulates sensitivity of ovarian cancer cells to cisplatin by altering the HMGB1-mediated autophagic response. Oncogene 31 1055-1064. (https://doi.org/10.1038/ onc.2011.290)

Zhang Y, Liao Z, Zhang LJ \& Xiao HT 2015 The utility of chloroquine in cancer therapy. Current Medical Research and Opinion 31 1009-1013. (https://doi.org/10.1185/03007995.2015.1025731)

Zhang Y, Luo L, Zheng X \& Yu T 2016 An advanced orthotopic ovarian cancer model in mice for therapeutic trials. BioMed Research International 2016 2585787. (https://doi.org/10.1155/2016/2585787)

Zhang Y, Li J \& Yu T 2017 Pharmacokinetic profiles of cancer sonochemotherapy. Expert Opinion on Drug Delivery 14 745-753. (https://doi.org/10.1080/17425247.2016.1232248)

Received in final form 22 October 2017

Accepted 24 October 2017

Accepted preprint published online 24 October 2017 